\title{
Growing points in Neotropical migratory bird conservation
}

Millions of birds migrate every year from breeding grounds in North America to wintering grounds in tropical America. Some 50\% of the species which breed in North America spend the winter in the Neotropics. Although these migrations have been studied quite extensively, austral, altitudinal and local movements of birds are also very important but poorly documented to date.

It is critical to have a clear understanding of the range of avian migration in the Neotropics to design and implement bird conservation strategies at both the national and regional level. These strategies were addressed by a three-day symposium and workshop on migrant birds held at the Neotropical Ornithological Congress in Quito, Ecuador, 3-5 November 1991. This publication discusses and documents various migratory bird strategies between North and South America and within Latin America through the selection of relevant papers presented at the Congress (some of which, it should be noted, have been revised and extended by their authors since 1991 to take account of subsequent perceptions or information).

Indeed, this volume is the first to concentrate on the conservation of birds that migrate within Latin America. Described here for the first time are regular migratory movements within tropical latitudes that are exceptionally widespread. Latitudinal migration within the tropics and seasonal movements of birds up (where breeding takes place) and down mountain slopes are undertaken by many species. Some are spectacular creatures (quetzals, bellbirds), but most are small fruit- or nectar-eaters, which as adults are similar to Nearctic migrants and rely on insect food to nourish their small nestlings. Altitudinal migration has not received much attention until recently, a fact which highlights the continued significance of basic research to the conservation of avifaunas within Latin America; without such research these new complexities might have remained unknown, to the detriment of conservation efforts. These papers, together with those on temperate to tropical migration, both boreal and austral, provide a first glimpse of the entire Western Hemisphere migration system in all its variety, excepting coastal and marine birds.

The chapters range from synthetic reviews of migration and its systems (Stiles, Chesser, Levey and Stiles) through studies of seasonal migration through regions or areas (Antas, Stiles, Nocedal, Rappole and Ramos, Vannini, Wunderle and Waide), of homing abilities in supposed residents (Ramos and Rappole) and of altitudinal migration in two frugivores (Powell and Bjork, Rosselli) to a treatment of competition for resources as a force affecting distributions among migrants (Greenberg, Salgado and Macias), with a review of the synergism between lowered reproductive success and forest fragmentation in some Nearctic breeders (Robinson and Wilcove). Taken as a whole, the chapters 
include both intensive, highly documented studies and broader, more speculative discussions of the causes of population declines in migrant birds.

It is hoped that this volume will help to stimulate more research into the ecological and man-induced reasons for the patterns of migration and decline here described. Conservation measures become more difficult when birds are migratory, no matter what the directions they take. Of course, this volume is not able to provide a comprehensive overview of the Western Hemisphere migration systems because our understanding is still in a pioneering state. Much more research is needed, and quickly. Our goal, therefore, is to highlight these papers as "growing points" to stimulate and organize key research areas and to provide additional information to integrate the chapters as much as possible.

F. Gary Stiles's contribution provides a natural introduction by highlighting several themes picked up in other papers. By presenting a realistic view of the cultural and political climate towards research and conservation in Latin America, he provides an inspiration to individuals living there to begin or to continue long-term research. He illustrates how, with a limited budget, limited equipment and few helpers, major advances can be made in our understanding of the behaviour and ecology of migrant and resident birds. Back yard ornithology is cutting edge if your back yard is in the tropics.

\section{Acknowledgements}

We would like to thank the authors for their patience and assistance with both the symposium and the preparation of this book. We thank Christoph Imboden and the staff at the BirdLife International Secretariat for their support, particularly Nigel Collar and Martin Kelsey for their help with editing and Gina Pfaff for preparing the manuscripts. We also gratefully acknowledge the reviewers of these papers: R. Askins, W. Belton, J. R. Faaborg, J. W. Fitzpatrick, M. S. Foster, R. Greenberg, D. W. Levey, J. F. Lynch, D. McDonald, D. Petit, G. V. Powell, F. Moore, D. H. Morse, H. A. Raffaele, J. Rappole, F. G. Stiles, B. Trent Thomas and J. M. Wunderle. Finally, we thank the University of Chicago Press for permission to provide an extended Spanish summary of the paper by Levey and Stiles which appeared in American Naturalist 122 (1992): 447-476.

EUGENE S. MORTON

KIMBERLEY YOUNG

MARIO A. RAMOS 